\title{
Performance management and diversity in higher education: an introduction
}

\author{
Ana I. Melo ${ }^{1,2,3}$ (D) Hugo Figueiredo ${ }^{1,2,4}$
}

Received: 9 May 2019 / Accepted: 26 July 2019 / Published online: 31 August 2019

(C) The European Higher Education Society 2019

In recent years, higher education institutions have become somewhat fixated on the issue of performance. This has been visible in rankings (Williams and de Rassenfosse 2014), attempts to create national centres of excellence based on exceptional performance (Hazelkorn 2015), and performance-based funding (Rutherford and Rabovsky 2014), especially in relation to research performance (Anninos 2014; Bazeley 2010; Edgar and Geare 2013).

Considering how common performance management systems have become, one might expect to find a consensus that these are generally successful (Gerrish 2015). Although many researchers argue performance information contributes for organisations to be more strategic and efficient, enabling service users and policy makers to hold them more accountable (Moynihan et al. 2011), a growing body of literature identifies potential policy design and implementation problems. In fact, some authors state that many performance management systems in public service organisations (including in higher education institutions) are poorly applied (Frederickson and Frederickson 2006; Radin 1998), or used (Melo et al. 2010; Melo and Sarrico 2015). According to Birdsall (2018, p. 671), for example, "politics, resource constraints, organizational capacity, institutional differences, and the nature of public goods and services create a number of complications that may make implementing performance management systems ineffective or harmful for public organizations". Moreover, there are growing concerns that performance management systems may introduce perverse incentives, induce gaming and divert attention from unmeasured, but important organizational outputs or outcomes (Bohte and Meier 2000; Birdsall 2018; Gerrish 2015; Heinrich 2004; Moynihan 2006; Piotrowski and Rosenbloom 2002; Radin 2006). In fact, Bohte and Meier (2000) argue that using performance data to evaluate the work of organizations often means focusing on

Ana I. Melo

ana.melo@ua.pt

1 CIPES - Centre for Research in Higher Education Policies, R. $1^{\circ}$ de Dezembro, 399, 4450-137 Matosinhos, Portugal

2 GOVCOPP - Research Unit on Governance, Competitiveness and Public Policies, University of Aveiro, Aveiro, Portugal

3 ESTGA - School of Technology and Management, University of Aveiro, Aveiro, Portugal

4 DEGEIT, University of Aveiro, Aveiro, Portugal 
outputs rather than substantive contributions to social outcomes. Also, many of the identified problems may be caused by the difficulty to design policies that "accommodate the diverse capacities, resources, and missions of target organizations" (Birdsall 2018, p. 672).

Nowhere this sounds truer than in the case of higher education institutions, considering their complex and multi-mission nature (Winston 1999; Weisbrod et al. 2008). Their specificity may be pointed out at in a number of different ways. Musselin (2006), for example, refers to the loose coupling and the technologically unclear (partly undefined) nature of both teaching and research to argue for such exceptionality. From an organisational perspective, albeit in different ways, both aspects tilt knowledge ownership away from top-level administrators or managers. In fact, authority over knowledge creation or transmission activities is rarely defined by formal or explicit contracts, but rather by de facto ownership of information (Aghion et al. 2013). Technological uncertainty in this sense weakens the hierarchical control over the content of work. This creates the space for classic principal-agent problems (Beerkens 2017) within higher education institutions and a possible dissonance between their envisaged strategic orientation and the actions of teaching and research staff. This is hardly their exclusive. However, the autonomous or isolated nature of much academic work (whether we are talking about individuals or teams), and its causal uncertainty, does tend to give further strategic authority to academics or research teams. While team autonomy is a common characteristic of large private companies pushing the technological frontier, for example, a stronger alignment between topmanagement strategy and their employees' motivational direction is more common.

Musselin's (2006) notion of loose coupling refers mainly to the possibility of conducting teaching or research activities in relative isolation. However, a different type of decoupling between teaching and research - may equally be present as research objectives may not necessarily align with broader employability or citizenship goals attributed to teaching activities. Similarly, academics may engage (or not) in research or other academic activities that require or are defined by a greater engagement with external stakeholders (whether this refers to the commercialisation of their academic knowledge or other forms of collaborative research, consulting or other third-mission or extension activities) (Goddard 2009; Perkmann et al. 2013). This variety of missions, and the fact that external stakeholders, in many cases, approach higher education institutions looking for new solutions to existing problems, adds to the information asymmetries between their leadership structures and their staff. The notion of hybrid organisations (Kleimann 2018) is equally used to denote the diversity and plurality of activities, logics and identities within higher education institutions.

The challenge, therefore, becomes that of carving and fine-tuning a set of incentives that are coherent and encompassing enough to accommodate and foster such diversity of activities. The governance of higher education institutions may be subject, however, to a number of important trade-offs. Governing through excessive formalisation of procedures and hierarchisation is likely to destruct rather than stimulate diversity and the creation of distinctive resources (Musselin 2006). In addition, many of the referred activities are shaped by or require a strong public ethos which may be at odds with a performance-based rationale, essentially due to the difficulty in objectively measuring the outcomes of some of these third-mission activities. Indeed, in the case of French public universities, Chatelain-Ponroy et al. (2018) show that academics' commitment to performance-based objectives is negatively correlated with such publicness. Where should the governance needle lie then?

In view of such challenges, fostering mission diversity at the system-level is, in principle, desirable. This is particularly so the more higher education institutions approach the status of complete organisations with distinctive or unique strategic profiles, greater autonomy and 
coherent hierarchical and incentive structures (Seeber et al. 2015). Fostering diversity at the system-level would therefore help to ensure that institutions with strong basic research capabilities and distinctive commercialisation competences could co-exist with institutions with greater focus on engaging with a wider array of external, often local or regional stakeholders. The latter type of regionally-relevant institutions could also exist alongside other institutions with greater international excellence ambitions. Also, public- or citizenshipminded institutions, on the one hand, and employability-driven or clearly vocationaloriented institutions, on the other, could cater for specific publics, not the least in view of the increasing massification of higher education in many countries. Such a system-oriented approach to diversity could equally have the advantage of focusing on public service delivery as a whole giving greater attention to the complementarities among different institutions (Osborne 2010).

While desirable, such mission identity and horizontal diversity is far from being an automatic goal. First, growing diversity within larger, ever more encompassing multiversities (Kerr 1963) may co-exist with the increasing stratification of higher education systems and the downplay (of the status and relevance) of vocational-oriented institutions or single-mission universities (Antonowicz et al. 2018). Such stratification may refer, among other dimensions, to the access to financial resources, to the signalling or perception of competence to solve both basic research and societal problems, but equally to the ability to attract students, as the "university" brand gains ground over other institutional types. Second, even as the upward (towards different types of research or third-mission activities) or downward (towards different publics) reach of such institutions increases, growing strategic diversity across the system is also not necessarily guaranteed. Again, as Antonowicz et al. (2018) summarise, global, national or regional competitive pressures may force higher education institutions to mimic rather than to develop their own distinctive mission profiles. Paradoxically, specialised universities, while facing such competitive pressures, appear to be those where academics are more likely to report sharing a distinctive identity (Seeber et al. 2015). Third, and of special relevance to this special issue, performance measurement and management regimes, implemented at the national- or system-level, may also enter the boundaries of higher education institutions, limit and influence their strategic autonomy and create further complexity to the hierarchical governance that ought to be put in place to accommodate further diversity in the system (Enders et al. 2013). In addition to the information ownership problems we already alluded to, the ability of centrally imposed performance assessment frameworks to, first, recognise such diversity and, second, virtuously interact with each institution's specificity, becomes therefore an additional and crucial dimension. The reliance on rankings or on measurement systems that focus solely on internationally recognized research and tie it to the notion of excellence are classic examples of how mission diversity can be implicitly curtailed.

The aim of the special issue is then to explore how performance management systems can be designed and implemented to support or hinder the promotion of mission diversity within HE systems. It reunites and improves on a number of contributions that were central to the 8th Track - Performance and Assessment - of the 39th Annual EAIR Forum held in Porto. Specifically, all these contributions help us to reflect on the way central- or system-level performance assessment frameworks adequately accommodate or can be used to foster diversity. Four main types of contributions were selected: i) papers that look at mission diversity in higher education systems through the lenses of institutional classifications; ii) papers that look at how higher education leaders can develop and implement performance 
measures that adequately recognize and measure mission diversity at the system-level; iii) papers that look at the management of diversity at the organizational level and the conflicting demands it poses to institutions; and finally iv) papers that look at how finance mechanisms can work to support or hinder such objective of mission diversity.

Institutional classifications constitute obvious legal and steering tools to promote horizontal diversity. Borden and McCormick's paper looks precisely at the potential of current and future classification systems in the U.S. to promote and support such institutional differentiation. The authors argue that classification systems, by recognizing both vertical and horizontal differentiation, offer promise for better contextualizing measures of institutional performance. This can involve both delineating the appropriate comparative context for assessing performance and tailoring the selection of measures that are appropriate to a given group of institutions. The authors recognize, however, that this approach will likely complicate the use of performance information: instead of universally applying a single set of performance metrics and associated performance standards, both will be subject to a logic of contingency that links performance information and judgments to the institution type. The performance system is thus rendered more complex and less accessible to those who may lack a sophisticated understanding of institutional differentiation and its relevance to performance assessment. At the same time, the authors recognize that such complexity coupled with conflicting pressures (e.g. rankings) and incoherent incentives can cut across the intended consequences of classifications, making these unable to stop vertical stratification. The authors also defend, however, that a classification system offers the added benefit of, precisely, revealing the unintended and undesirable biases in the design of a performance assessment regime, making these viable tools to guide performance assessment mechanisms to acknowledge and accommodate the complexity of higher education.

Regarding the second topic, both the Roessler and Catacutan and the Biscaia et al. papers address the limitations of traditional performance assessment mechanisms that focus solely on academic research and its impact. The former paper looks at this issue from the perspective of the growing importance of Third Mission activities where academia and the non-academic environment work together and interact mutually. According to the authors, existing University Ranking systems, for example, still tend to blur differences between higher education institutions by mostly focusing on a narrow set of research activities. The increased breadth, diversity and complexity of higher education institutions' missions are, instead, repeatedly overlooked. Using the results of 618 higher education institutions in the U-Multirank ranking (Van Vught and Ziegele 2010), Roessler and Catacutan show the possibilities to measure other missions, such as international orientation and regional engagement. To these authors, only when measurement systems, such as university rankings, take the different missions explicitly into account, are they able to make mission diversity visible and highlight the distinctiveness of each institutions' strategic resources (including their host regions) and strengths, increasing transparency.

Biscaia et al.'s paper also departs from the limitations of performance measurement frameworks that adopt a narrow definition of research, focusing, instead, on the mission particularities of Portuguese polytechnic higher education institutions. The authors develop and empirically validate a set of performance indicators to account and give greater visibility to the wide set of research and cultural creation activities in which these institutions are involved. They equally devise measures to account for the broader regional impact of such groups of institutions. Five dimensions of research and extension activities are proposed and, for each one of them, a set of performance indicators is defined. The authors claim that the proposed 
indicators can be used at the system-level to support performance reporting to relevant governance bodies in binary systems, and also as a management and self-evaluation tool, allowing higher education institutions themselves to define their own profile, establish their own goals and the strategies to achieve them.

Katarina Larsen's paper is, in turn, implicitly aligned with both the idea of the incompleteness of higher education institutions and the complexity of hierarchical governance at the system-level we alluded to above. The author focuses on the experience of setting-up Centres of Excellence both in Sweden and Japan. Centres of Excellence juggle a series of different pressures, ranging from the need to guarantee academic relevance and international excellence, to secure sufficient autonomy to allow enough breathing space for fundamental innovations and guarantee sufficient engagement from industry partners. The author documents that such contrasting missions are maintained through dual logics of institutions relating both to autonomy and industry collaboration. The author argues, in particular, that it is the development of an autonomous logic that guides their research activities and strategic choices regarding the direction of research and the choice of collaboration partners. At the same time, Centres of Excellence are also developing strategies to manage the dilemmas they are facing, including: the need to secure competitive funding based on scientific excellence and on being evaluated on the external impact of the scientific output and on collaboration activities; and the need to accommodate typical New Public Management-style management templates and practices that give a greater role to managerial control. The author argues that, despite these complex collaborative ties with university management, government and industry, Centres of Excellence can contribute to the differentiation of the strategic profiles of universities if their own organizational nature is taken explicitly into consideration. For example, the study shows that long-term funding contributes to give flexibility to these centres in setting their own agenda and core activities.

Finally, and further pursuing this link between funding and diversity, the final two papers describe the implementation of Performance Agreements in the Netherlands and Norway. A growing number of governments have been introducing elements of performance in funding mechanisms for higher education institutions. Performance Agreements offer, in principle, the possibility of maintaining such a link, and also of accommodating the strategic diversity that can both emerge spontaneously from within higher education institutions or be required from them to face new societal challenges (e.g. catering for new student publics or supporting regional development processes through greater engagement with local actors). The availability of indicator frameworks that can capture the full diversity of activities carried out by HEIs as discussed above - may in that sense be seen as an essential facilitator of their implementation. How this virtuous loop is actually implemented in practice, however, is still subject to great uncertainty and worth documenting, not the least due to the relative novelty of such agreements. Ingvild Larsen et al.'s paper starts, therefore, by describing and analyzing the context, process and framework for the introduction of such agreements by the Norwegian government. The authors are optimistic that these can be used as tools for creating further diversity in the system, possibly strengthening institutional strategic capacity among institutions. While acknowledging that their implementation in Norway has enjoyed broad institutional support and benefits from the consensus-based approach of the Norwegian regulation of higher education, the authors also show that the process has been slow due mainly to the still limited capacity for horizontal coordination and the difficult choices of prioritizing some areas and tasks over others. They go on to argue that, in face of these challenges, the process benefits greatly from the commitment to a better division of labour between higher education 
institutions on the part of the Norwegian governance bodies. The consistent profiling of higher education institutions, in particular, was a crucial first-step in the process of identifying target areas, objectives and relevant indicators to be implemented in Performance Agreements.

Jongbloed et al.'s paper, in turn, goes a step further in evaluating the relative success of the implementation of such agreements in the Netherlands. That is done by looking at completion rates as well as other indicators of educational quality, as Dutch Performance Agreements explicitly aim at increasing the diversity of educational offerings. The results of the paper, however, do not demonstrate a clear link between the implementation of such programs, further differentiation of study programs and successful outcomes. Both Universities of Applied Sciences (UAS) and Research Universities (RUs) appear to have had incentives to widen the spread of their education offerings. Yet, the former group appears to have exhibited a much less successful performance regarding completion rates. The authors, however, argue that the implementation of Performance Agreements had many advantages, not the least by providing greater visibility, as well as policy attention to issues of educational success, institutional profiling, involvement of external stakeholders, transparency and accountability. At the same time, and seen from the perspective of institutions, the earlier implementation of such agreements in the Netherlands still flirted with some of the dangers of New Public Management-styled interventions: the prevalence of quantitative outputs over qualitative outcomes and the loss of institutional autonomy, the imposition of additional administrative costs, increased distance from academic staff and students and the prevalence of vertical accountability over horizontal accountability (towards the various stakeholders of tertiary institutions). These aspects have created enough resistance from higher education institutions leadership structures. As such, current versions of Performance Agreements in the Netherlands now focus solely on the quality of education, rely to a greater extent on qualitative assessments and grant more autonomy to institutions than earlier incarnations.

In conclusion, what this and the remaining papers in this special issue show is how delicate the balance between vertical steering and the need to respect institutional boundaries (and, ultimately, the autonomy of academic staff) must be. At the same time, as we argued, making sure that strengthening higher education institutions strategical autonomy results in greater mission diversity at the system-level is far from guaranteed, as powerful drivers of homogeneity and stratification are equally present in higher education systems across most developed economies. Policy makers and higher education leaders are therefore between a rock and a hard place when it comes to devising performance management systems that promote further diversity and need to act both with great flexibility (between institutions) and precision (within higher education institutions).

\section{References}

Aghion, P., Bloom, N., \& Van Reenen, J. (2013). Incomplete contracts and the internal organization of firms. Journal of Law, Economics, and Organization, 30, i37-i63. https://doi.org/10.1093/jleo/ewt003.

Anninos, L. N. (2014). Research performance evaluation: Some critical thoughts on standard bibliometric indicators. Studies in Higher Education, 39(9), 1542-1561.

Antonowicz, D., Cantwell, B., Froumin, I., Jones, G., Marginson, S., \& Pinheiro, R. (2018). Horizontal diversity. In B. Cantwell, S. Marginson, \& A. Smolentseva (Eds.), High participation systems of higher education (pp. 94-124). Oxford: Oxford University Press. 
Bazeley, P. (2010). Conceptualising research performance. Studies in Higher Education, 35(8), 889-903.

Beerkens, M. (2017). Information issues, higher education markets. Encyclopedia of International Higher Education Systems and Institutions. https://doi.org/10.1007/978-94-017-9553-1 104-1.

Birdsall, C. (2018). Performance management in public higher education: Unintended consequences and the implications of organizational diversity. Public Performance \& Management Review, 41(4), 669-695.

Bohte, J., \& Meier, K. J. (2000). Goal displacement: Assessing the motivation for organizational cheating. Public Administration Review, 60(2), 173-182.

Chatelain-Ponroy, S., Mignot-Gérard, S., Musselin, C., \& Sponem, S. (2018). Is commitment to performancebased management compatible with commitment to university "publicness"? Academics' values in French universities. Organization Studies, 39, 1377-1401. https://doi.org/10.1177/0170840617717099.

Edgar, F., \& Geare, A. (2013). Factors Influencing University research performance. Studies in Higher Education, 38(5), 774-792.

Enders, J., de Boer, H., \& Weyer, E. (2013). Regulatory autonomy and performance: The reform of higher education re-visited. Higher Education, 65(1), 5-23.

Frederickson, D. G., \& Frederickson, H. G. (2006). Measuring the performance of the hollow state. Washington, DC: Georgetown University Press.

Gerrish, E. (2015). The impact of performance management on performance in public organizations: A metaanalysis. Public Administration Review, 76(1), 48-66.

Goddard, J. (2009). Reinventing the Civic University. London: NESTA Making Innovation Flourish.

Hazelkorn, E. (2015). Rankings and the reshaping of higher education: The battle for world-class excellence (2nd ed.). Basingstoke: Palgrave Macmillan.

Heinrich, C. J. (2004). Improving public-sector performance management: One step forward, two steps Back? Public Finance and Management, 4(3), 317-351.

Kerr, C. (1963). The uses of the university. Cambridge: Harvard University Press.

Kleimann, B. (2018). (German) Universities as multiple hybrid organizations. Higher Education, 77, 1085-1102. https://doi.org/10.1007/s10734-018-0321-7.

Melo, A. I., \& Sarrico, C. S. (2015). Performance management systems and their influence on the governance structures of Portuguese universities: A case study. In Incentives and performance (pp. 413-430). Cham: Springer International Publishing. https://doi.org/10.1007/978-3-319-09785-5_25.

Melo, A. I., Sarrico, C. S., \& Radnor, Z. (2010). The influence of performance management systems on key actors in universities: The case of an English university. Public Management Review, 12(2), 233-254.

Moynihan, D. P. (2006). What do we talk about when we talk about performance? Dialogue theory and performance budgeting. Journal of Public Administration Research and Theory, 16(2), 151-168.

Moynihan, D. P., Fernandez, S., Kim, S., LeRoux, K. M., Piotrowski, S. J., Wright, B. E., \& Yang, K. (2011). Performance regimes amidst governance complexity. Journal of Public Administration Research and Theory, 21(Supplement 1), i141-i155.

Musselin C. (2006). Are universities specific organisations?. In Krücken G., Kosmützky A., \& Torka M. (Eds.), Towards a multiversity? Universities between global trends and national traditions (pp. 63-84). Bielefeld: Transcript Verlag.

Osborne, S. P. (2010). Delivering public services: Time for a new theory. Public Management Review, 12(1), 110.

Perkmann, M., Tartari, V., McKelvey, M., Autio, E., Broström, A., D’Este, P., Fini, R., Geuna, A., Grimaldi, R., Hughes, A., Krabel, S., Kitson, M., Llerena, P., Lissoni, F., Salter, A., \& Sobrero, M. (2013). Academic engagement and commercialisation: A review of the literature on university-industry relations. Research Policy, 42(2), 423-442.

Piotrowski, S. J., \& Rosenbloom, D. H. (2002). Nonmission-based values in results-oriented public management: The case of freedom of information. Public Administration Review, 62(6), 643-657.

Radin, B. A. (1998). The Government Performance and Results Act (GPRA): Hydra-headed monster or flexible management tool? Public Administration Review, 58(4), 307-316.

Radin, B. (2006). Challenging the performance movement. Washington, DC: Georgetown University Press.

Rutherford, A., \& Rabovsky, T. (2014). Evaluating impacts of performance funding policies on student outcomes in higher education. The Annals of the American Academy, 655(1), 185-208.

Seeber, M., Lepori, B., Montauti, M., Enders, J., de Boer, H., Weyer, E., Bleiklie, I., Hope, K., Michelsen, S., Mathisen, G. N., Frølich, N., Scordato, L., Stensaker, B., Waagene, E., Dragsic, Z., Kretek, P., Krücken, G., Magalhães, A., Ribeiro, F. M., Sousa, S., Veiga, A., Santiago, R., Marini, G., \& Reale, E. (2015). European universities as complete organizations? Understanding identity, hierarchy and rationality in public organizations. Public Management Review, 17(10), 1444-1474. 
Van Vught, F., \& Ziegele, F., (2010). U-Multirank: Design and testing the feasibility of a multi-dimensional global university ranking. Twente: University of Twente, CHEPS.

Weisbrod, B. A., Ballou, J. P., \& Asch, E. D. (2008). Mission and money. Cambridge: Cambridge University Press.

Williams, R., \& de Rassenfosse, G. (2014). Pitfalls in aggregating performance measures in higher education. Studies in Higher Education, 41(1), 51-62.

Winston, G. C. (1999). Subsidies, hierarchy and peers: The awkward economics of higher education. Journal of Economic Perspectives, 13, 13-36. https://doi.org/10.1257/jep.13.1.13.

Publisher's note Springer Nature remains neutral with regard to jurisdictional claims in published maps and institutional affiliations. 